\title{
Augmented reality in brain tumor surgery using the microscope focal point as the virtual pointer
}

\author{
Mario Ammirati ${ }^{1,2}$ D
}

Received: 4 November 2021 / Accepted: 5 November 2021 / Published online: 24 November 2021

(c) The Author(s), under exclusive licence to Springer-Verlag GmbH Austria, part of Springer Nature 2021

The paper by Rothe et al. essentially deals with the use of the microscope focal point as the virtual pointer during brain tumor surgery. As the navigation image or a segmented target is shown in the microscope oculars, either as a picture in picture or as an overlay display, together with the live microscopic image, the whole process may be categorized as "augmented reality" [1].

This process was first implemented by the Zeiss MKM microscope in the 1990s; since then, all major microscope manufacturers have implemented the use of the microscope focal point as a virtual pointer as well as the capability to inject images into the microscope oculars.

It is quite intuitive and well known that there are several advantages in using the microscope focal point as a virtual pointer during microscopic brain tumor surgery, the main one being that it is not necessary to switch to a real pointer with the often necessary and time-consuming adjustments in the working distance and microscope positioning.
Mario Ammirati

lemoko60@me.com

1 Center for Biotechnology Department of Biology, College of Science and Technology, Temple University, Philadelphia, PA, USA

2 Neurotherapeutic Research Program @ Sbarro Health Organization at Temple University, 1900 North 12th Street, Biolife Science Building, Suite 431, Philadelphia, PA 19122, USA
Overall, the authors did a good job of bringing to the fore the major advantages of AR brain surgery in a navigated environment where the microscope focal point is used as the virtual pointer. We fully agree that a real 3D display of segmented targets/structures compared to an outline display would be a major step forward and we look forward to further communication by the authors along those lines.

\section{References}

1. Douglas DB, Wilke CA, Gibson D, Petricoin EF, Liotta L (2017) Virtual reality and augmented reality: advances in surgery. Biol Eng Med 3(1):1-8. https://doi.org/10.15761/BEM.1000131

Publisher's note Springer Nature remains neutral with regard to jurisdictional claims in published maps and institutional affiliations. 